\title{
Spreading order: religion, cooperative niche construction, and risky coordination problems
}

\author{
Joseph Bulbulia
}

Received: 25 October 2010/Accepted: 27 September 2011/Published online: 25 October 2011

(C) The Author(s) 2011. This article is published with open access at Springerlink.com

\begin{abstract}
Adaptationists explain the evolution of religion from the cooperative effects of religious commitments, but which cooperation problem does religion evolve to solve? I focus on a class of symmetrical coordination problems for which there are two pure Nash equilibriums: (1) ALL COOPERATE, which is efficient but relies on full cooperation; (2) ALL DEFECT, which is inefficient but pays regardless of what others choose. Formal and experimental studies reveal that for such risky coordination problems, only the defection equilibrium is evolutionarily stable. The following makes sense of otherwise puzzling properties of religious cognition and cultures as features of cooperative designs that evolve to stabilise such risky exchange. The model is interesting because it explains lingering puzzles in the data on religion, and better integrates evolutionary theories of religion with recent, well-motivated models of cooperative niche construction.
\end{abstract}

Keywords Cooperation $\cdot$ Culture $\cdot$ Evolution $\cdot$ Niche construction $\cdot$ Religion $\cdot$ Stag hunt

\section{Introduction}

On September 3rd 1967, Sweden became the final country in continental Europe to make the change from left to right-handed driving. "Högertrafikomlåggningen" or "The Right-hand Traffic Diversion" was widely unpopular. Referendums were hotly debated among Swedish politicians, and most Swedes resisted the change. Counting in favour of the switch were the economic advantages of harmonising road conventions with Sweden's neighbours and a mounting death toll from confused foreign motorists. To promote general knowledge of "Dagen-H" (H-Day), the

\footnotetext{
J. Bulbulia ( $\bowtie)$

Victoria University of Wellington, FHSS, Wellington, New Zealand

e-mail: joseph.bulbulia@vuw.ac.nz
} 
Swedish government sponsored lively festivals, advertising campaigns featuring scantily clad women, and a song contest for which the winner was "Håll dig till höger, Svensson" or "Keep to the right, Svensson." Even bespoke underwear displaying the Dagen-H emblem - an automobile smoothly transitioning from left to right-was marketed to the public. By the morning of Dagen-H, the Swedish government had spent millions of kronor on the campaign. For all the hype and worry, however, Dagen-H transpired without accident. September 1967 saw an overall decline in Swedish road deaths. ${ }^{1}$ Dagen-H, and the broader trend to conformity to which it belongs, illustrates several important, general, and I think underrated points about the mechanisms that evolve to assure large-scale cooperation among strangers. ${ }^{2}$

Part 1 explains why risky coordination problems present a pervasive challenge to the evolution of cooperation.

Part 2 describes an evolutionary model for religion called charismatic niche construction, which shows how religion may evolve to assure efficient but risky exchange by modulating social/affective cognition.

Part 3 uses this model to make sense of certain data about religion that remain puzzling on other evolutionary approaches.

Part 4 uses recent experimental results to explain some of the cultural and cognitive mechanisms by which religions may assure efficient exchange.

While the main purpose of this article is to improve understanding for evolutionary religious studies, I also hope that my analysis will contribute to a larger conversation about the importance of cooperative niche construction to explaining aspects of the human condition (Sterelny 2011).

\section{Part 1. Why risky coordination problems are interesting}

Defection need not be motivated from theft

While evolutionary researchers often assimilate cooperation's problems to variations of the Prisoner's Dilemma, it has long been understood that cooperation may fail without any special risk from theft (Binmore 1998; Calcott 2008; Schelling 1960). Cooperation problems admit of varieties, many of which are better modelled by a different game. I follow Schelling in thinking that:

[w]e should probably identify as the generic problem [of cooperation], not the inefficient equilibrium of the prisoner's dilemma, but all the situations in which equilibria achieved by unconcerted or undisciplined action are inefficient-the situations in which everyone could be better off, or some

\footnotetext{
${ }^{1}$ http://www.time.com/time/magazine/article/0,9171,941144,00.html.

2 Dagen-H marked the end of a gradual progression toward rightward driving in continental Europe that appears to have begun with the French Revolution (Young 1998; Kincaid 1986).
} 
Fig. 1 The stag hunt: payoffs: $\mathrm{HI}>\mathrm{LO}>0 *=$ equilibrium; $*^{1}>*^{2}$

\begin{tabular}{c|cc|cc|}
\multicolumn{1}{c}{} & \multicolumn{2}{c}{ Svensson Stag } & \multicolumn{2}{c|}{ Svensson Hare } \\
\cline { 2 - 5 } Betty Stag & $\mathrm{HI}^{* 1}$ & \multicolumn{2}{c|}{$\mathrm{LO}$} \\
\cline { 2 - 4 } Betty Hare & & 0 & \\
\cline { 2 - 4 } & & & & $\mathrm{LO}^{* 2}$ \\
\hline & & & $\mathrm{LO}^{* 2}$ & \\
\hline
\end{tabular}

collective total could be made larger, by concerted or disciplined or organised or regulated or centralized decisions (Schelling 1978: location 3110).

I will be interested in coordination problems with risk.

\section{Example: The stag hunt}

Mention "risky coordination problem" and economists will respond "The Stag Hunt." 3 The game imagines that partners are hunters who may choose to hunt stags or to hunt hares. Stag and hare hunting are imagined to be mutually exclusive strategies. Each hunter does best when all collectively hunt stags, for stags are invariably captured when all chase stags, but never otherwise. ${ }^{4}$ To hunt a stag is to cooperate. A hunter may also choose to hunt hares. The hare benefit pays less than the successful stag benefit, though it pays independently of what other partners choose. To hunt a hare is to defect. When cooperation fails, Betty's decision to hunt stags wears the opportunity costs of a lost hare. When cooperation would have succeeded had Betty cooperated, Betty wears the opportunity costs of a lost stag portion (Fig. 1).

Here, only the risk dominant equilibrium is evolutionarily stable.

There are two equilibriums for this game: (1) ALL COOPERATE, the Pareto optimal equilibrium; (2) ALL DEFECT, the risk dominant equilibrium. If ALL COOPERATE no one can be made better off than by cooperating. ${ }^{5}$ If at least one partner defects, no one can be made better of than by defecting too. Allowing strategies to evolve, which of these equilibriums is reached depends on the initial sample of strategies, the number of players, and the differences in the relevant payoffs (Young 1998). Assuming randomness for an ordinary Stag Hunt, however, only the risk dominant equilibrium evolves: only defection is stochastically stable (Young 1993). The reason for this is easy to understand. The advantage of cooperation is both hard won and fragile: rare defector mutants can destroy cooperation's benefit; rare cooperative mutants cannot restore it.

\footnotetext{
3 The Stag Hunt is extensively discussed in Skyrms (2004). The game derives from a passage in Rousseau's Discourses (Rousseau 1755), which I discuss below.

4 To allow for both absolute and relative benefits from cooperation it might seem important to add to the condition that a successful hunt requires the cooperation of "all but one." Otherwise a lone defector could gain a relative advantage by spoiling cooperation's benefit for others. To avoid this problem, I assume some form of multi-level selection sufficient to favour cooperative over non-cooperative benefits.

5 I ignore the mixed equilibrium because there are no conditions under which it is evolutionarily stable.
} 


\section{Example: The tragedy of the Meadow}

Sometimes, what might appear superficially to present a Prisoner's Dilemma or Tragedy of the Commons is better construed as a risky coordination dilemma or Stag Hunt. In David Hume's parable for collective action:

Two neighbours may agree to drain a meadow, which they possess in common; because it is easy for them to know each others mind; and each must perceive, that the immediate consequence of his failing in his part is the abandoning the whole project. But it is very difficult, and indeed impossible, that a thousand persons should agree in any such action; it being difficult for them to concert so complicated a design, and still more difficult for them to execute it; while each seeks a pretext to free himself of the trouble and expense, and would lay the whole burden on others (Hume 1739, 3.2.7.).

If we imagine that partners may "lay the burden to others who will assume it," then the tragedy of the meadow describes a tragedy of the commons. However if we imagine that the "trouble and expense" of cooperating brings compensating benefits for which a collective effort is needed, then the tragedy of the meadow is better formalised as a Stag Hunt (Skyrms 2004). Tragedies of the commons are often better described as what I will call tragedies of the meadow (see: Ostrom 1990: chapter 1).

Tragedies of the meadow should not be consigned to the dustbin of irrelevant formal models. Experimental findings consistently reveal the fragility of risky coordination problems (see: Camerer 2003; Van Huyck et al. 1990). Outside the laboratory, such problems are not always solved, and solutions, where they arise, are not invincible to evolution's entropic trend. ${ }^{6}$

Why coordination requires assurance mechanisms

Partners find a common interest in resolving tragedies of the meadow. Solutions do not require changing the payoffs of cooperation and defection. Dagen- $\mathrm{H}$ offers an example of a design that supports cooperative interaction by rendering the coordination equilibrium predictable in a potentially lethal game. Though it often takes an accident to notice, the driving game is a horrifically dangerous activity. Driving involves moving heavy machinery at speeds an order of magnitude or more faster than our terrestrial custom, in the fog, in the dark, around tight bends, on water and ice, on streets strewn with hazards. Moreover the benefits of driving are not independent of the actions of others: by taking to the roads we place our lives in the hands of strangers, ${ }^{7}$ a significant fraction of whom may be counted on to be intoxicated, distracted, drowsy, or otherwise unfit and incompetent. Margins for error reduce to centimetres. There is ample scope for randomness to unleash nightmarish tricks. Person-to-person signalling is limited and evanescent. Erroneous

\footnotetext{
${ }^{6}$ Discussed in (Bicchieri 2006). Corruption offers a familiar example of coordination's failure: nearly everyone loses from corruption, though once established, corruption remains difficult to overcome.

7 At the time of H-Dagen, for example, Sweden's population was just shy of eight million.
} 
prediction in the driving game spares no cost and no anguish. Each year tens of thousands of lives are destroyed from driving. Yet the core problems of the driving game are repeatedly solved. ${ }^{8}$ The specific problem of the sideward travel dilemma is universally solved. Moreover solutions are not unique to driving games, but rather generalise across an intricate tangle of anonymous relationships and interactions, defeating the entropic trend that formal models consistently predict. Why do we choose cooperation in situations where benefits rely on the responses of strangers? ${ }^{9}$

Clearly assurance mechanisms evolve to enable coordination's benefits. Partners risk losing these benefits by going it alone, so ignore assurance mechanisms at their peril. That assurance mechanisms are ratified from a convergence of cooperative interests stands at the foundation of Hume's explanation for governing authority. In the passage immediately following his description of coordination's failure in the meadow, Hume writes:

Political society easily remedies... these inconveniences. Magistrates find an immediate interest in the interest of any considerable part of their subjects. They need consult no body but themselves to form any scheme for the promoting of that interest. And as the failure of any one piece in the execution is connected, though not immediately, with the failure of the whole, they

\footnotetext{
${ }^{8}$ Consider Samoa, which in 2009 became one the few countries after World War I to shift from the right to left-sided driving convention. The proposal for this change was also met with hostile public criticism. After the decision was announced, an organisation called PASS-People Against Switching Sidesbrought suit against their government. There were widespread public revolts, with several townships promising public noncompliance. The proposed law change was described in the press as "a nightmare;" a prominent professor from Monash University testified in court that more accidents and road deaths could be expected if the change were to proceed; see: http://news.theage.com.au/breaking-newsworld/samoans-revolt-against-road-side-switch-20090821-esz4.html. On September 6, 2009, amid forecasts of chaos, destruction, and death, Prime Minister Tuilaepa Sailele Malielegaoi informed drivers by radio that the leftward convention had become law. For a brief period government vehicles drove through the empty streets using loud sirens to signal the transition. Despite forecasts for widespread social calamity the transition occurred smoothly, in conditions that had appeared to many uncertain and dangerous, yet without any major accident reported, see: http://www.howwedrive.com/category/ traffichistory/.

9 Richerson and Gil-White comment:
}

Suppose you stroll to the corner restaurant for breakfast: eggs, bacon, and a glass of orange juice. A simple activity? No. Mind-numbing complexity is more like it. A farmer in Virginia produced your egg, another in Florida your orange juice, and yet another in the Midwest your bacon. Different truckers brought each of these to a supermarket. The restaurateur then bought them there and had them prepared for you. Seven people are involved in your "simple" activity? Well, no. This is a caricature. Just for starters, the egg farmer/capitalist hires several workers to operate considerable equipment, all of which was purchased from other companies, made up of capitalists and workers, which in turn bought their parts from yet other companies, which... (the mind reels). Your day has barely begun, and a few dollars worth of breakfast has already brought an army of considerable size to your service (Gil-White and Richerson 2003).

Similarly, a comedy news agency ran a spoof headline: "Life Put In Hands Of 2,000 Complete Strangers Every Single Day" (see: http://www.theonion.com/articles/report-life-put-in-hands-of-2000complete-stranger,20640/).

However, the joke almost certainly underestimates the magnitude of such mortal dependence. Betty flies at 40,000 feet above the surface of the earth in a Boeing 777-300, a machine composed of over 150,000 complex parts, each of which will have been designed, assembled, inspected, and refurbished by teams of individuals who would not grieve her loss. Why fly? Why leave home? 
prevent that failure, because they find no interest in it, either immediate or remote. Thus bridges are built; harbours opened; ramparts raised; canals formed; fleets equipped; and armies disciplined every where, by the care of government, which, though composed of men subject to all human infirmities, becomes, by one of the finest and most subtle inventions imaginable, a composition, which is, in some measure, exempted from all these infirmities (Hume 1739: 3.2.7).

Hume is correct to notice that governing institutions, "the finest and most subtle inventions imaginable," evolve to coordinate the material interactions of agents at cooperative equilibriums in the various games of life. Hume also understood, correctly, that governing authority need not depend on the existence, effectiveness, or competence of magistrates: a constellation of unstated conventions also evolves to coordinate partners at efficient equilibriums in the games of life, "acquiring force by a slow progression, and by our repeated experience of the inconveniences of transgressing [them]"(Hume 1739: 3.2.2). Hume's appeal to formal and informal conventions as solutions to cooperation's problems finds many contemporary followers. For example, David Lewis writes:

Our experience of a general conformity in the past leads us, by force of precedent, to expect a like conformity in the future. And our expectation of future conformity is a reason to go on conforming, since to conform if others do is to achieve a coordination equilibrium... Once the process gets started, we have a metastable self-perpetuating system of preferences, expectations, and actions capable of persisting indefinitely (Lewis 1969: location 410).

Yet what enables conventions to be metastable assurance mechanisms? This question requires us to consider what is required of an assurance device. Lewis suggests: "[c]oordination may be rationally achieved with the aid of a system of concordant mutual expectations, of first or higher orders, about the agents actions, preferences, and rationality" (Lewis 1969: location 302). Yet how can Betty know what others expect of each other, as they reflect on each other's expectations "at higher orders?" Such concordant expectations would appear to invite an interminable regress of second-guessing among anonymous partners who inhabit large and anonymous groups.

Notably, such a regress may be avoided wherever partners discover "focal points," Schelling's term for features of a situation that dictate "each person's expectation of what the other expects him to expect to be expected to do" (Schelling 1960: 57). Focal points offer something like a publically consultable record that instructs partners about what each should do, much like a telephone book tells Betty, Svensson, and other strangers their telephone numbers. While one can always pretend to be a skeptic about what others know, cooperation's problem is not that of refuting skepticism but rather of obtaining sufficient motivation for sufficiently many partners to afford cooperation's rewards in Rousseau's forest and Hume's meadow. The analysis of conventions as sufficiently clear public instructions, sustained from mutually satisfying benefits, appears plausible and has many supporters (Bacharach 2006; Sugden 2003)]. 
Why instructions are poor assurance mechanisms

Elinor Ostrom expresses her dissatisfaction with the instructionalist paradigm in the following way:

Simply explaining puzzling findings post hoc, as "they must somehow share some norms," is not a satisfactory strategy in the long run [and does not] explain fully how individuals do overcome social dilemmas... [We] need to dig into the analysis of institutions so that we can understand how individuals adopt norms as well as rules to overcome social dilemmas (Ostrom 2005: location 2676).

Why do cooperative instructions cause cooperation? Recall that we are interested in solutions to cooperation problems at coordination's fragile limits, where the differences between cooperation's dependent benefits and defection's independent benefits may be small; where the opportunity costs from cooperative decisions may be great; or where successful exchange requires the cooperative actions of potentially many anonymous partners. While solutions to such problems might appear trivial, the instability of efficient exchange at the risky end of coordination's spectrum arises from the simplest cases.

To see this, consider how coordination may fail partners who are able to communicate before they interact. At first blush, language would appear to be an especially powerful assurance mechanism because it allows partners to name the efficient equilibrium as their focal point: "Tomorrow at $7 \mathrm{am}$, we drain the meadow. Those who do not turn up will be beaten severely." Indeed, the results of experimental games show that coordination dilemmas are reliably assured from pregame communication even without such draconian threats. While subjects who cannot communicate always learn the risk dominate equilibrium, those who can communicate always learn the Pareto efficient equilibrium (Kim and Sobel 1995), even in situations where cooperation may be threatened by theft (Silk et al. 2000).

Does pre-game communication assure efficient exchange because language affords exquisitely precise and clear instructions? It is difficult to know whether experimental subjects who exchange comments before laboratory games have not already cultivated cooperative habits from systems whose complexity far exceeds the instructional capacity of language. We should not conclude from such experiments that it is the propositional content of pre-game locutions that is doing the motivational work. Similarly we should not infer from such experiments that instructions assure real world coordination dilemmas. Indeed, we have independent reason to doubt the plausibility of such an inference.

Problems for the reliability of language may arise even when interactions are restricted to two communicating partners. We imagine that Betty and Svensson are in a one-off stag hunt. However in this version of the game we replace the equality of unilateral and mutual defection with an inequality $(\mathrm{H} \dagger$ for you when you defect and they cooperate $>$ LO for you when you defect and they defect). Mutual cooperation still pays both partners best, however we now assume that a defecting partner does nearly as well when defecting at another's cooperation as when mutual cooperation succeeds (Fig. 2) [see: Binmore 2007. Note: we still assume that the 
values in the matrices relate to fitness outcomes, so that defecting agent will not evolve to seek relative advantages from spite].

In this modified Stag Hunt, Betty and Svensson will both desire mutual cooperation, however the information conveyed by any proposition attempting to coax the other into cooperating would appear to be insufficient, on its own, to assure their cooperation's future. This is because both partners will wish the other to cooperate, and (by assumption) to believe that cooperation will occur, even if each feels too risk-averse to choose cooperation.

This problem for language generalises to ordinary stag hunts (i.e. those resembling Fig. 1). Rubinstein considers the case in which small probabilities for error are permitted in the delivery or interpretation of a message instructing an efficient but risky equilibrium (Rubinstein 1989). If Betty may doubt whether Svensson has received her message or correctly interpreted it, she may doubt Svensson's cooperative response. Knowing that Betty may doubt his cooperative response, Svensson may doubt whether Betty will act on her instructions, and so on. Rubinstein points out that the more messages that partners convey across a noisy medium, the greater the probability of coordination's failure as confidence factors taking values less than one multiply into each other with the production of each new message (Rubinstein 1989; Binmore 2008: 20)]. Setting aside the two player case, we can see how this problem that Rubinstein notices for the predictive value of naked instructions magnifies among anonymous partners, who must factor the probability that some anonymous creeping skeptic in the mission critical group for cooperation's advantage will lose confidence and defect.

Might symbolic culture do better than language? In an important paper, Alvard and Nolin notice that whale hunting in Lamalera Indonesia closely resembles a Stag Hunt (Alvard and Nolin 2002). Whales are sought after meat packages, but their capture is risky. Crews hunt whales by harpooning the animal causing it to swim and dive to exhaustion. During the hunt, whaling vessels may be towed far out to sea; crew are sometimes ejected; ships occasionally sink: "By almost any standard, whale hunting is dangerous" (Alvard and Nolin 2002: 539). Such risks, however, are mitigated by collective hunting in which many boats give support to the harpooning vessel. Any decision to hunt a whale carries the lost opportunity of fishing, a safer bet. In Lamalera Indonesia, whales are stags and fish are hares.

Alvard and Nolin make sense of numerous cultural factors as subtle assurance mechanisms for the whale hunt. For example, the authors point out that an intricate thicket of norms govern the distribution of whale portions. From these norms, motivations to help with the whale hunt find support from the predictability of (a sufficiently) satisfactory division of spoils (Alvard and Nolin 2002: 547). Moreover, the norm for hunting is itself well-established, hence past hunts are taken to be precedents for future hunts. Finally, and important to the discussion below, the authors argue that rituals function as pre-game communication devices. Prior to the whale-hunting season villagers gather for Tobo Nama Fata, a celebration that involves the crews, craftsman, and heads of local clans. The ritual enables relevant parties "to discuss any mishaps, accidents, slights, and problems from the previous whaling season, clear the air of any ill will, and suggest solutions for the upcoming year. In this regard, [the ritual] is a formal forum for the discussion and 
Fig. 2 The modified stag hunt: payoffs: $\mathrm{HI}>\mathrm{H} \dagger>\mathrm{LO}>0 *=$ equilibrium; $*^{1}>*^{2}$

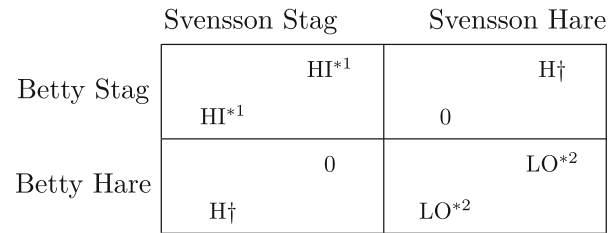

establishment of norms" (Alvard and Nolin 2002: 549). ${ }^{10}$ Do norms, precedents, decrees, and rituals assure solutions to tragedies of the meadow as "pre-game communication" devices? Perhaps, though not merely because they convey knowledge or instructions. Notably, to speak of past norms, precedents, and rituals does not explain the evolutionary stability of such devices; nor does it explain how partners respond cooperatively to novel problems; nor does it explain how partners recover confidence from cooperation's inevitable defeats, when a whale escapes, after a ship sinks or a harpoon tragically misfires. We have noticed that for fragile exchange, pre-game instructions would appear too flimsy to reliably assure coordination at its risky limit.

The shortcomings of the instructionalist paradigm comes into sharp relief when we consider the core problems of the Stag Hunt as Rousseau imagined them in his original parable:

Were it a matter of catching a deer, everyone was quite aware that he must faithfully keep to his post in order to achieve this purpose, but if a hare happened to pass within reach of one of them, no doubt he would have pursued it without giving it a second though, and that, having obtained his prey, he cared very little about causing his companions to miss theirs (Rousseau 1755: location 1216).

Rousseau's stag hunters know what is expected of them. Their problem is not one of instructions or knowledge, but rather one that finds its roots in a distracting temptation for a safe gain and that flourishes in an absence of regret over following it. If languages, conventions, pre-game communication, rituals and other assurance devices evolve to assure efficient but risky exchange it is not simply because such factors convey knowledge or instructions: "Everyone was quite aware..." The success of any reliable assurance mechanism should rather depend on the manner by which it modulates social and affective cognition in the face of temptation and risk. I next consider how religions are fitted to provide an especially powerful form of social-affective assurance.

\section{Part 2. Charismatic niche construction for risky coordination problems}

I call the psychological characteristics associated with commitments and practices respecting gods, religious traits. I assume that various institutional, developmental, and genetic factors interact to produce religious traits. The frequency and character

\footnotetext{
10 Similarly, Michael Suk Young Chwe conjectures that "public rituals be understood as social practices that generate common knowledge" (Chwe 2001: location 77).
} 
of the religious traits of one's social cohort is likely to form part of this complex causal story. I call the various causes of religious traits-genetic, epigenetic, accidental... etc.-religions. This term dignifies ignorance with a label, for we know relatively little about the complex factors that interact to express and sustain religious traits. In the next section, I consider three basic design features that we might expect from any reliable assurance mechanism for coordination in Rousseau's forest and Hume's meadow. Later I will use these features to explain puzzling data on religions.

\section{Charismatic governance}

I use the term "charisma" in Max Weber's sense as a perceived quality of a person or situation that tends to evoke strong obedience and loyalty (Weber 1958). The charismatic model starts with the observation that wherever factors may be rigged to express commanding motivations that also align behaviours to cooperative goals, tragedies of the forest and meadow may be avoided. I assume that such designs do not evolve merely to communicate instructions but more fundamentally to regiment social emotions.

Hobbes famously described our natural state as "a war... of every man against every man;" from which a Leviathan releases us as "a common power to keep [us] all in awe" (Hobbes 1651: pt.1 ch.13). Hobbes's concept of "awe" points in the direction of a satisfactory assurance mechanism because it suggests an overwhelming emotion capable of distracting partners from hare chasing. However it would be a mistake to restrict attention to purely awesome cognitive governance. A more fundamental property of an effective assurance mechanism is that it reliably offloads strategic decision-making from individuals to subjugating factors in their world. Such factors would appear to be especially effective wherever they reliably evoke obedience and loyalty, which is to say, when they are charismatic in Weber's sense.

\section{Ecological engineering}

For cooperation to pay, assurance mechanisms must not only reliably govern cooperative cognition, they must do so in synchrony for sufficiently many members of the relevant exchange group for cooperation to pay. The demand for synchrony imposes strict requirements on the spatial and temporal properties of stable assurance mechanisms. Regarding the geo-temporal properties of such designs, there appear to be broadly two classes of solution.

\section{Focal designs}

Focal mechanisms may evolve to affect those citizens of a cooperative tribe who share contemporaneous access to the same governing factors:

\section{Betty $\longleftarrow$ AWE $\longrightarrow$ Svensson}

Given the benefits of charismatic designs that are capable of simultaneously reaching many partners, we might predict that such mechanisms have been 
harboured, and perhaps continue to be maintained, in widely accessible features of many human habitats. Focussing on religious cultures, central and prominent places of worship such as The Temple of Karnak in Egypt, The Temple of Hera at Olympia, The Aztec Templo Mayor at the centre of Tenochtitlan (in present day Mexico City), The Hagia Sophia in Istanbul, the statue of Jesus high above Buenos Aires, and other salient but apparently worse-than-useless structures offer prime candidates (when considered in light of the institutional, educational, and ritual edifices of which they form a part) for social-affective governing channels. The independent emergence of central temple structures at the geographical centre of each of the original urban centres of the middle Holocene (Wheatley 1971) also finds an explanation in an evolutionary model for large-scale cooperation in which focal, charismatic factors evolve to affect obedience to efficient exchange and loyalty to strangers. Again, we would not expect that such designs would evolve to instruct partners; rather we would expect charismatic designs to evolve to pervasively and reliably apprise and subordinate social affective cognition at large social scales. Below we shall consider preliminary evidence for such focal designs.

\section{Diffuse designs}

Cooperative ecologies would be strongly constrained if they were to require that all partners congregate at roughly the same location and time. However, charismatic factors that are scattered throughout the geographical and temporal contexts of transacting partners may afford sufficient coverage to underwrite efficient exchange, many persons to many governing nodes. For this reason we might also expect diffuse designs to evolve to address the limitations of focal pathways.

$$
\left[\mathbf{A W E}_{1} \longrightarrow \text { Betty }\right] \leftrightarrow\left[\text { Svensson } \longleftarrow \mathbf{A W E}_{2}\right]
$$

The benefits of diffusion may help to explain the emergence and conservation of relatively private affective cultures and practices: home altars, private worship, mass produced symbolic regalia and religious texts, and other such outputs which notably lack any clear means-end advantage or utility. The advantage of diffuse distributions is that they do not limit partners to one geo-temporal local, allowing charismatic factors to synchronise the cooperative behaviours of anonymous partners across large geographically regions.

Notably, the conservation of dispersed and private religious practices and artefacts remains otherwise difficult to explain. For example, cognitive theories of both focal and diffuse religio-symbolic cultures have concentrated attention to memory effects (Whitehouse 2004), but it is unclear why the systems that generate such seemingly arbitrary memories would be conserved as grains in selection's balance tilt against them. The ultimate explanation for such galvanising and controlling cultures is, by contrast, well-explained from a model in which religious cultures evolve to avert tragedies of Rousseau's forest and Hume's meadow. 


\section{Temporal engineering}

Reverse engineering the temporal properties of assurance mechanisms may help researchers to investigate the temporal organisation of religious practices. The charismatic model predicts that schedules of exposure to cooperative agonists will favour a recurrence rate that is sufficient to maintain cooperative behaviours above a minimal threshold for each mission critical member of a cooperative group. Such requirements may help to explain the maintenance of otherwise costly festivals, pilgrimages, public orations, parades, sacrifices, executions, and similarly repeated productions as factors that maintain cooperative motivations at sufficient levels. Beyond their descriptive qualities, however, we shall see that little is known about the evolution of the temporal properties of religions, or whether they manifest designs that answer functional demands.

\section{Part 3. How the charismatic model explains puzzles in the data on religious cooperation}

Religious practices bring opportunity costs, risks, and material expenses, ostensibly with few economic or otherwise practical benefits (Atran and Norenzayan 2004; Irons 2001; Sosis 2003; Sterelny 2007). It is for this reason that religions would appear to be worse than useless, yet they pervade, and continue to pervade, all known societies. Why are religious inefficiencies conserved in nature's unforgiving economy? Charismatic niche construction answers this cost puzzle by approaching religions as evolved assurance mechanisms for risky coordination problems. The model improves on existing theories by explaining otherwise puzzling facts about religion. ${ }^{11}$ Before considering such puzzles, consider why many naturalists find evolutionary theories of religion plausible.

Why cooperative theories of religion are plausible

Cooperation theories of religion are hardly new. The fourth century Greek thinker Critias speculated:

[H] umans established laws for punishment, that justice might rule over the tribe of mortals, and wanton injury be subdued ... the laws held [mortals] back from deeds of open violence, but still such deeds were done in secret, then, I think, some shrewd man first, a man in judgment wise, found for mortals the fear of gods, thereby to frighten the wicked should they even act or speak or scheme in secret... Even if you plan in silence some evil deed it will not be hidden from the gods: for discernment lies in them ... (Critias 2010).

\footnotetext{
${ }^{11}$ I limit my focus to puzzles arising from cooperation theories of religion. Though I cannot consider them here, I note that there are evolutionary approaches to religion that do not appeal to religion's cooperative or otherwise functional effects [for example, Boyer and Lienard (2006)].
} 
Writing during the Chinese Warring States period, the ancient Chinese philosopher Mozi similarly conjectured:

[T] he awareness of ghosts and spirits is such that it is not possible to do something in the darkest places, whether in wide marshes, in mountains and forests, or in deep ravines without the awareness of ghosts and spirits certainly knowing of it. The punishments of the ghosts and spirits are such that it is not possible [to avoid them], whether rich and noble and [having a populace that is] numerous and strong, or with brave and powerful forces, or with strong shields and sharp weapons, for the punishments of ghosts and spirits will undoubtedly overcome these things (Johnston 2010, § 31.17: 299).

While fuctional theories of religion are old news, renewed interest in religions as evolved cooperation mechanisms has emerged from quantitative evidence demonstrating religion's prosocial effects. Many studies find significant correlations between levels of religious commitments and levels of cooperative solidarity (Atkinson and Bourrat 2010; Ginges et al. 2009; Johnson 2005). Those who believe in moralising gods tend to endorse strong within-group moralities. Moreover, levels of religious commitment appear to increase in response to coalitional threats (Bellah 1967; Chen 2010; Lanman 2009; Sosis and Bressler 2003). Thus, precisely at those moments when we would expect to find increasing efficiency and realism, religion turns up its volume. Such remarkable effects are well explained by socialfunctionalist models of religion.

The evidence for religion's prosocial effects is not confined to specific cultures or time periods. Peter Turchin's recent book War and Peace and War persuasively argues that religious solidarity has repeatedly facilitated the mobilisation of partners into highly cohesive units, contributing to the rise of empires across the globe for at least the past two and a half millenniums (Turchin 2006). Turchin calls this quality of religious solidary "asabiya," a concept he borrows from the fourteenth century political philosopher Ibn Khaldun: "Although Ibn Khaldun does not say it directly, it seems that the religious feeling is a sort of asabiya, but one that can unite broader groups than tribal-level asabiya" (Turchin 2006: location 1504). ${ }^{12}$

Note that religious prosociality improves on cooperative mechanisms that employ (purely) arbitrary symbolic devices to maintain group boundaries (for example "green beards") from commitments regarding supernatural causation that strongly motivate within-group prosociality. According to those who believe in gods, it is "not possible to do something in the darkest places, whether in wide marshes, in mountains and forests, or in deep ravines without the awareness of ghosts and spirits certainly knowing of it" (Johnston 2010: § 31.17: 299)—an alarming thought to any would-be defector. Similarly arresting: "[e]ven if you plan in silence some evil deed it will not be hidden from the gods" (Critias 2010). While the data on religious cooperation suggest that cooperative theories of religion are on the right track, nevertheless certain puzzles arise when religion is modelled as an

\footnotetext{
12 For quantitative studies of the relative advantages of religious organisations to relevantly similar secular counterparts see: Sosis and Bressler (2003).
} 
adaptation for cooperation in a tragedy of the commons, rather than for cooperation in Rousseau's forest or Hume's meadow.

Puzzle: why is religious cooperation stable?

Naturalists do not suppose that ghosts and gods actually reward and punish cooperative behaviours. Why, then, do free-riders not invade pious groups, destroying religion's advantage? A plausible answer to the stability problem comes from commitment signalling theory, which observes that wherever religious traits are (1) reliably associated with cooperative traits, (2) hard-to-fake, and (3) projectable, such traits may function as both motivators and signals of cooperative futures. The idea is that (1) religious piety causes within-group cooperation and (2) hard-to-fake expressions of piety assure this cooperation against impious defectors who cannot manage to produce pious expressions convincingly.

While I think signalling theory remains important to the project of explaining religion's evolution, it has its limits: it does not readily explain religious cooperation in anonymous worlds where partners cannot rely on interpersonal signalling. The charismatic model, on the other hand, faces no problem from the stability of anonymous cooperation because it suggests that religions evolve, at least in part, to solve risky coordination problems. The model advises that researchers take a break from asking how religion polices Prisoner's Dilemmas and instead consider how religion averts tragedies of the meadow.

Puzzle: why are religious ecologies sufficient to enhance cooperation without belief?

The experimental literatures have demonstrated subtle cooperative influences from religious cues among participants who do not profess any religious beliefs. For example Mazar and colleagues found that both religious and non-religious (Canadian) students were equally likely to become more resistant to cheating temptations after attempting to recollect the Ten Commandments, irrespective of how many commandments they managed to recall or whether they believed in God (Mazar et al. 2008). This result is consistent with a larger body of research showing strong cooperative modulation in response to cues that suggest religious rules and/or ghostly observers-here too without any clear dependency on supernatural beliefs (reviewed in: Bulbulia 2009). Such effects are best explained as arising from lowlevel sensory-motor processes, relatively automatically, from an implicit association of supernatural cues with pro-social norms (Randolph-Seng and Nielsen 2008). Yet if cues are sufficient to cause cooperation, what advantages do costly religious beliefs bring to cooperative interactions? A cost problem for religious belief remains.

Here too the charismatic model translates a puzzle into evidence. The model predicts the expression of cooperation relatively automatically in response to religious cues. While the specific relationship of religious belief to cooperative outcomes cannot be determined from a few experiments, the charismatic model clarifies why governing obedience and loyalty of the kind sufficient to stabilise risky exchange should not stand or fall with anything so fragile as an explicit belief in supernatural 
powers, even if the model allows that supernatural beliefs may interact with other cognitive processes to amplify prosocial commitments. Knowing nothing else, we would predict a pervasive involvement of social-affective cognition in response to factors that evolved for cooperative governance, aspects of which may evolve to weakly control even those who disbelieve.

Puzzle: why are religious beliefs insufficient to support cooperation?

Darely and Batson's Good Samaritan experiment offers the classic demonstration of how seemingly small variables can overwhelm the prosocial influences of religious commitments, even when religion is strongly cued (Darley and Batson 1973; Norenzayan and Shariff 2008). In this study, the authors instructed participants at the Princeton Theological Seminary to give a sermon on a Gospel story extolling the virtues of helping needy strangers. The control group was instructed to give a job talk. Along the way, participants encountered a person in need. The sermon rehearsal had no effect on helping behaviour. Nor did levels of religious belief anticipate helping behaviour. The only significant predictor of helping behaviour was the degree to which participants were in a hurry $(63 \%$ helped in the low hurry condition, $45 \%$ in the moderate hurry condition; $10 \%$ in the high hurry condition). This experiment is important because it shows that religious beliefs need not invariably support cooperation, at least cooperation of the kind that religious doctrines enjoin. Recent studies reveal similar context dependent variability. For example Malhotra found that while Christians were more likely to offer money to a charity after attending church service, such effects vanished the next day, and did not return until the following holy day (Malhotra 2010). Would any cooperation have been observed on Sundays among church going participants who were in a hurry?

While the effects of religious contexts and commitments remain poorly understood, the data suggest that religious beliefs may be insufficient to strengthen cooperative tendencies among the pious. The broader point, then, is that religious beliefs appear to be neither necessary nor sufficient to assure efficient exchange.

I think it would be an error, however, to infer that explicit religious commitments do not matter to cooperative outcomes in tragedies of the meadow. The complexity of how context affects social-interactive outcomes is indeed the central, frequently overlooked message of Darley and Bateson's original paper:

It is hard to think of a context in which norms concerning helping those in distress are more salient than for a person thinking about the Good Samaritan, ... It is difficult not to conclude from this that the frequently cited explanation that ethics becomes a luxury as the speed of our daily lives increases is at least an accurate description... But perhaps this is not entirely accurate ... According to the reflections of some of the subjects, it would be inaccurate to say that they realized the victim's possible distress, then chose to ignore it; instead, because of the time pressures, they did not perceive the scene in the alley as an occasion for an ethical decision. For other subjects it seems more accurate to conclude that they decided not to stop. They appeared aroused and anxious after the encounter in the alley. For these subjects, what were the 
elements of the choice that they were making? Why were the seminarians hurrying? Because the experimenter, whom the subject was helping, was depending on him to get to a particular place quickly. In other words, he was in conflict between stopping to help the victim and continuing on his way to help the experimenter. And this is often true of people in a hurry; they hurry because somebody depends on their being somewhere. Conflict, rather than callousness, can explain their failure to stop (Darley and Batson 1973: 107-108).

Darley and Batson notice cooperative effects may exhibit complex situational dependencies, here related to allocations of responsibility and time. For some participants, the situations perhaps caused a moral blindness, for others, a heightened sense of duty to authority. Such outcomes were artefacts of the experimental design. More generally, beyond their superficial descriptive properties, we know relatively little about how natural and social human ecologies regulate commerce-how they modify attention, a sense of urgency, loyalties, and generate other cognitive effects relevant to efficient exchange. Nor do we fully understand the degree to which the effects of such mechanisms are mismatched to our current circumstances. In the next section, however, I review preliminary evidence showing how religious commitments interact with ritual contexts to affect perceptions of solidarity, trust, and to underwrite revealed preferences for cooperation.

\section{Part 4. Evidence for charismatic control}

The charismatic model resolves certain puzzles in the data on religions, but how do religious practices specifically affect the committed? I begin by examining recent experiments showing social-regulatory effects of low-level body movements and postures.

Evidence of automatic solidarity from focal ritual movements: laboratory studies

Recollecting his World War II military cadet training, the historian William McNeal reports:

Words are inadequate to describe the emotion aroused by prolonged movement in unison that drilling involved. A sense of pervasive well-being is what we recall; more specifically, a strange sense of personal enlargement; a sort of swelling out, becoming bigger than life, thanks to participation in collective ritual... Obviously, something visceral was at work; something, we later concluded, far older than language and critically important to human history, because the emotion it arouses constitutes an indefinitely expansible basis for social cohesion among any and every group that keeps together in time, moving big muscles together and chanting, singing or shooting rhythmically (McNeill 1995; see also: Haidt et al. 2008; Wilson 2007).

Some initial quantitative support for the muscular bonding hypothesis comes from Wiltermuth and Heath's recent experiment investigating the effects of synchronous movements and song on cooperative interactions (Wiltermuth and 
Heath 2008). The experiment randomly assigned participants to groups of three that engaged in activities that varied in levels of body synchrony. Manipulations involved passing cups and singing the Canadian National Anthem, "O Canada." (Participants were American university students). Participants in groups who moved and/or sang in synchrony were observed to be more cooperative in subsequent iterated public goods games than were asynchronous and passive control groups. Moreover participants in synchronous conditions reported enhanced feelings of being on the same team and reported greater perceptions of similarity to their counterparts. Such participants also tended to trust each other more. Importantly, feelings of being on the same team partially mediated the effect of synchrony on cooperation, suggesting that cooperation may be evoked, at least in part, by a perceived sense of solidarity amongst synchronous performers, an effect consistent with the sort of automatic prosocial affect that benefits cooperation in Rousseau's forest and Hume's meadow. ${ }^{13}$

Laboratory data therefore offer some quantitative support for effects in the neighbourhood of "muscular bonding." Such evidence is interesting because it demonstrates the production of cooperative behaviours from factors that do not depend on any partner specific signalling of pre-existing virtues.

Evidence of automatic solidarity from an interaction of focal ritual movements and sacred values: field studies

A lingering question in the experimental data on muscular bonding is the degree to which explicit commitments_-values and beliefs_-affect partnerships in naturally occurring cooperative arenas. To better understand the effects of collective rituals in vivo, Fischer and colleagues investigated interactions between sacred values and levels of synchrony among nine religious and secular groups whose ritual participants varied in their levels of behavioural synchrony and declared sacred values. The team hypothesised that rituals with higher levels of body synchrony and higher levels of reported sacred values would be associated with the greatest amounts of solidarity, as measured by a standard economic game and a battery of explicit scales. ${ }^{14}$ The team found a significant effect of synchrony on trust, with the lowest trust found in non-synchrony groups, intermediate trust in factional synchrony groups and highest levels of trust in groups with full synchrony. Consistent with laboratory research (reviewed in subsection "Evidence of automatic solidarity from focal ritual movements: laboratory studies"), these results show a significant correlation between trust and naturally occurring synchronous rituals. We also tested a process mechanism by which synchrony leads to pro-social

\footnotetext{
${ }^{13}$ For similar results see: Hove and Risen (2009 and Valdesolo and DeSteno (2011).

14 A total of 113 participants from nine different community groups participated. Coding was based on observations during the group activity. Synchrony was coded into "group synchrony" (whole group performing the same movements or vocalizations in time with each other for $>30$ min; yoga; capoeira [Brazilian martial arts]; Buddhist chanting; Kirtan [Hindu devotional singing]); "factional synchrony" (subgroups performing exact movements or vocalizations that are unique, but complementary to whole group for $>30$ min; Brazilian drumming group; choir; Christian church service); and "no synchrony" (cross-country running group; social poker).
} 
behaviour by estimating a path model in MPlus, finding that synchrony had a direct effect on trust, entitativity and sacred values. We thus found, interstingly, that only sacred values had a direct link to pro-social responses in the economic game.

These results are interesting because they show that synchronous body movements affect cooperation in naturally occurring rituals, and that sacred values may combine with synchrony to modulate particularly powerful pro-social behaviours. More generally, the results point to the importance of interactions between explicit judgments and low-level sensory and motor processing to cooperative decisions.

Evidence for a limited spread of solidarity from focal ritual movements: a Spanish firewalking ritual

A study of the heart rhythms of participants in a Spanish fire walking ritual sheds intriguing light on how rituals may strongly align certain core metabolic processes associated with social affect among both ritual participants and spectators (Konvalinka et al. 2011). Konvalinka, Xygalatas and their colleagues used recurrence quantification analysis (RQA) and cross-recurrence quantification analysis (CRQA) to quantify levels of shared arousal among participants and spectators to focal events of the ritual. Their results show remarkably high levels of heart rhythm sharing, which varied among specific groups of participants. The highest level of sharing was found among fellow firewalkers as they responded to the ordeals of other firewalkers. This suggests the involvement of empathetic mechanisms, the natures of which remain obscure. A significant but lesser degree of synchronicity was also observed in the heart rhythms of spectators who did not walk as they viewed the ordeals of firewalkers. This result suggests that ritually induced empathy may occur purely from simulation, in the absence of any shared experience of the ordeal. Here too, however, the underlying empathetic mechanisms remain unclear. Finally, onlookers with no previous association to any firewalker did not manifest any detectable level of shared arousal, suggesting that the social-cognitive effects of the firewalk ritual are not automatic but rather depend on prior exposure or familiarity with ritual participants.

The key finding for our purposes is that spectators who were related to at least one firewalker responded by sharing arousal to all firewalkers, including those firewalkers with whom they had no significant prior relationship. This surprising result reveals a potential pathway by which solidarity may extend from groups of known participants to groups of unknown participants. Some personal involvement with the trial by fire was necessary to evoke empathetic arousal, which when activated, radiated to networks of unfamiliar cohort. This experiment hints at impressive subtlety in the effects of a ritual on various types of participant, underscoring the perils of oversimplifying stories about how rituals orchestrate their social-cognitive effects.

Evidence of reward modulation from diffuse rituals: neural effects of repetitive prayer

In a recent fMRI study Schjoedt and colleagues compared the neural effects of highly religious Christians who frequently practice repetitive prayer ("The Lord's 
Prayer") with the effects of repeating familiar nursery rhymes (Schjoedt et al. 2008). The team found strong recruitment during the prayer condition in the dorsal striatum of religious participants, with the strength of such effects increasing with the frequency with which participants reported praying. Notably, the dorsal striatum is a region that contributes to the processing of reward expectations, and is enlisted during habit forming practices such as gambling and drug addiction.

For our purposes, Schjoedt and colleague's data are interesting because they show how religious emotions affect circuitry associated with reward expectations. Do prayerful traits evolve to support stag hunting and meadow draining? While the team did not record dependent variables related to solidarity and pro-sociality, various strands of evidence points to cooperative effects of prayer (Sosis and Ruffle 2003), suggesting this possibility as yet another intriguing line of investigation. The charismatic model is interesting because it suggests that practices of private prayer - and the costly institutional matrices that surrounds them-may have played a role, and perhaps continue to affect, the orchestration and stability of efficient exchange at large social scales.

Evidence of social affective modulation from diffuse rituals: neural effects of intercessory prayer

Uffe Schjoedt's team also investigated neural activations (fMRI) during "personal prayer," a regularly occurring practice in which Christians attempt to communicate with a perceived supernatural agent through internal, improvisational dialogue. Schjoedt and colleagues compared cortical activations during conditions in which Danish Christians made wishes to Santa Claus with conditions during which they prayed to God (Schjoedt et al. 2009). The authors found strong social mind involvement of brain regions associated with Theory of Mind. Specifically the team found enhanced activity in (1) the precuneus, an area that supports self-referential awareness; (2) the anterior medial prefrontal cortex, a region associated with selfawareness and mental perspective taking; (3) the temporopolar region, which contributes to autobiographical memory; and (4) the temporal parietal junction, an area associated with social prediction. No such activations were observed during the wishing to Santa Claus conditions.

For our present purposes, this study is interesting because it shows that Christians who pray strongly engage their social cognitive capacities. Consistent with the team's earlier repetitive prayer study, Schjoedt et al. found that the strength of neural responses to prayer were predicted by the frequency with which participants reported praying, suggesting a dependency of social-affective cognition on repetitive regimes, and presumably other social and educational externalities associated with religious enculturation. ${ }^{15}$

\footnotetext{
15 Schjoedt and colleagues studied Christians who practiced prayer frequently. The Lord's Prayer was uttered an average of 4.75 times per week, with a variance of 1-14 times. Personal Prayer was reported an average of 19.75 times per week, with a variance of 7-50 per week. All participants stated that they were strongly confident of "God's reciprocity."
} 
If personal prayer generates subjective experiences of a personal God felt to be a living reality, and God is believed to be capable of assuring future benefits, then it is at least plausible that believers will find motivation from personal prayer to act cooperatively in uncertain environments from an insensitivity to risks. Such a manufacture of religious experiences from personal prayer may also benefit cooperation from the intrinsic rewards that religious persons associate with acting in accordance with God's desires (Batson et al. 1993). A third channel for cooperative affect comes from the suppression of strategic Theory of Mind by strongly focussing attention to God's mind. While the cooperative effects of prayer need to be more rigorously investigated before we can understand the downstream socialcognitive consequences of prayer, this much is clear: tendencies to private religious experience would appear to be a dangerous habit unless they offered some compensatory support. On the other hand, wherever prayer is practiced widely, religiously distracted partners may flourish from the benefits of efficient exchange.

Evidence of hypnotic control: neural effects of religious authority

Another study from Schjoedt and his collaborators investigated the social-interactive effects of prayer. The authors were specifically interested in how religious authority affects religious experience, noting that many religious rituals are performed with help from religious experts: shamans, priests, prophets, and gurus. The authors conjectured that prior confidence in religious authority facilitates religious experience by positively adjusting expectations about ritual outcomes, which in turn supports confidence in religious authority (thus in part explaining the conservation both of religious elites and of religious experiences; Schjoedt et al. 2010).

To better evaluate this hypothesis, the team subjected both religious and secular participants to identical presentations of recorded healing prayers, but in conditions that varied information about the alleged healer's authority. In one condition, participants where told that a healing prayer was issued from a Christian "renown for his healing authority;" in a second condition, the speaker was described merely as a Christian, and in a third condition, as non-Christian. The researchers then compared differences in the neural signatures of participants as they listened to the prayer recording.

The team found no significant activations among non-believing participants during any of the three conditions. However among Christian participants, a strong down-regulation of executive cortex was observed in every condition with a linear tread showing the strongest responses under assumptions of healing authority, the next strongest responses from assumptions of shared religious membership, and the weakest responses in conditions that suggested no shared religious affiliation with the healer. Yet again neural signatures were most pronounced among Christians who reported the highest levels of prior religious commitment. ${ }^{16}$ Levels of frontal network down-regulation were also correlated with positive evaluations of the healer and with affirmations of the experience of God's presence while the prayers

\footnotetext{
16 Specifically, diminished activity was observed in the dorsolateral and medial prefrontal cortex, areas associated with planning and strategic perspective taking.
} 
were being uttered, giving support to the team's hypothesis that the framing of religious authority matters to the quality of religious cognition. Finally, Schjoedt and colleagues noted interesting parallels between neural responses to healing authority among Christian participants and neural responses to hypnotic induction reported in the fMRI literatures (Oakley et al. 2007; Oakley and Halligan 2009). The down-regulation of executive cortex during hypnosis has been observed to be similarly sensitive to prior expectations about the hypnotist's authority (MacLeod and Sheehan 2003).

For our purposes, Schjoedt's study is interesting because it reveals a hypnotic down-regulation of executive processing in response to religious authority. The absence of vigilance among those who attend to charismatic authority might appear un-evolvable in worlds where leaders can exploit their followers. Yet such hypnotic effects are consistent with the expectations of the charismatic model, which predicts the evolution of designs that displace strategic control from individuals to exogenous synchronising factors. ${ }^{17} \mathrm{We}$ would be gullible, however, to suppose that religious elites never defect for gain. A more plausible hypothesis is that elite power variously coordinates and exploits. An interesting implication of the Stag Hunt is that the most selfish of all partners will seek the benefit of universal cooperation most of all. Elite selfishness may sometimes be to the advantage of efficient exchange, if that selfishness is channelled to rallying the cooperation of others. I will not pursue the analysis of this point further here.

\section{Part 5. Conclusion}

J. L. Austin once quipped about philosophical writing: "there's the bit where you say it, and the bit where you take it back" (Austin 1962: 2). Before reviewing the bits I've said, let me take back some of the bits readers might have thought that I said.

Five limitations of the model

\section{Not all cooperation problems are Stag Hunts}

While I have followed Schelling in thinking that a better model for cooperation's problems is one that focuses to "the situations in which everyone could be better off, or some collective total could be made larger, by concerted or disciplined or organised or regulated or centralized decisions"(Schelling 1978: location 3110), I have not claimed, and do not believe, that all such cooperation problems are best modelled as Stag Hunts, tragedies of the meadow, or similar risky coordination dilemmas. Often it is unclear whether collective action problems can be described by simple game structures. An intriguing question is how we could know for certain

\footnotetext{
${ }^{17}$ Lee Cronk argues for an evolutionary model of religion in which religious elites hijack manipulative signals of virtue to exploit believers for personal gain (Cronk 1994). However Cronk's explanation does not clearly explain the persistence gullibility of followers.
} 
which game is relevant. By contrast we do know, trivially, that games oversimplify. Yet as readers of this journal are well aware, the utility of simplifying models is paid for by their power to explain more complex facts (Maynard Smith 1982: 9).

If it turns out that key features of many large scale cooperation problems are usefully approximated as risky coordination problems, then somewhat specific properties should be expected for mechanisms that evolve to assure them. I have used such expectations to explain otherwise mysterious properties of religious cultures and cognition, and to suggest fruitful avenues for research.

\section{Religion may evolve to police prisoner's dilemmas}

Religion may help to resolve Prisoner's Dilemmas in situations where interpersonal signalling is available. Notably, certain hard-to-fake religious signals may be assessed in a glance, enabling cooperative assortment in Prisoner's Dilemmas at bounded, but nevertheless large and impersonal social scales (Sosis 2005). Commitment signalling theory remains important to the evolutionary explanation of religion.

\section{Religion need not be "good"}

It probably goes without saying that religions may be adaptations without being currently adaptive (Sosis 2009). Moreover to evolve, religion need not be "good" in some moral or similarly qualified sense. Though attempting blanket judgements for anything so large and diverse as human religions seems to me an invitation to overstatement, a different issue. Finally, if we measure success in offspring, the most insular, undemocratic, and technologically backward religions are associated with extremely high birth-rates (Rowthorn 2011). Secular democracy appears to be the genetic poison (Newson 2009; Newson 2009). Here we find another case in which genetic interests differ from moral interests.

\section{Mechanisms other than religion assure risky coordination}

The evolutionary literature has focussed on norms for punishing defection (Boyd et al. 2005; Henrich 2006). Spatial properties and networks evolve cooperation. Repeated encounter converts a Prisoner's Dilemma into a game in which cooperation is strongly favoured (Binmore 2005). Nested structures of rules appear to stabilise cooperative institutions (Ostrom 2005: location 1359). Other cultural evolutionary models show that prestige and success biases may combine with imitative learning and virtue-signalling to favour religious cultural transmission (Henrich 2009). I do not infer that one model is right to the exclusion of others but rather that human-scale cooperation finds many tessellating supports.

\section{Favourable illustrations have been cherry-picked}

My argument for charismatic niche construction has assumed the form of an abductive inference, or "inference to the best explanation" for known data (Harman 1965). However, making sense of the results of experiments should not be confused 
with making experiments. Though abductive inference is important to scientific progress it is hardly sufficient. I have argued for the benefits of pursuing more finely discriminating experiments.

Five benefits of the model

\section{It is important to understand that not all defection is cheating}

"Defection" can be, and often should be dissociated from "cheating." Defection motivated from risk may remain even after every motivation to cheat has been removed. Moreover solutions to the problems of risk-avoidance may differ from solutions that police cooperation's theft. Evolutionary theories of religious cooperation have almost exclusively focussed on the cheating problem, but this has lead to anomalies. By thinking of religions as mechanisms that addresses other types of cooperation problem, however, such puzzles become tractable, and new pathways for empirical interest become evident.

\section{Instructionalist solutions do not explain the stability of risky exchange}

Pre-game communication, conventions, and other instructional devices cannot avert tragedies in Rousseau's forest and Hume's meadow because risky coordination problems are not problems of knowledge, common or otherwise. The benefits of cooperative actions in risky coordination games are conditional on the cooperative replies of others. I have argued that such risky cooperation is made stable from factors that evolve to cause cooperation at the level of interacting populations, irrespective of what partners may doubt and know.

\section{Puzzling data about religions are resolved as assurance mechanisms for risky exchange}

I have reviewed evidence suggesting that religion is associated with powerful group solidarity, that religious institutions tend to outcompete secular rivals, and that religions have long supported cooperation across linguistic, ethnic, and other cultural divides, binding groups together with an especially powerful form of solidarity. Such evidence supports longstanding conjectures that religions endure from their prosocial effects (see section "How the charismatic model explain puzzles in the data on religious cooperation").

However other evidence reveals that religious commitment is not necessary for religious environments to enhance cooperative sentiments and behaviours, that religious belief is not independently predictive of cooperative behaviour, and that circumstantial variables easily swamp expressed religious intentions. What to make of these contrasts?

While little is known about how religion specifically impacts on social-affective cognition, a point that cannot be over-emphasised, nevertheless early results suggest that religious environments are arrayed to strongly support cooperative outcomes. The automaticity of religiously supported cooperation is consistent with the design 
expectations of assurance mechanisms that evolve to stabilise efficient exchange by emotionally committing partners to efficient exchange, come what may. The evidence suggests that religious beliefs are best approached as components of such assurance mechanisms, elements of designs not wholes.

\section{Preliminary studies suggest religion's commanding prosocial effects}

Laboratory experiments show that entrainment in body motions and vocal rhythms tends to sustain cooperation over repeated interactions. Field studies reveal that a combination of synchronous movements with sacred values evokes the highest levels of cooperation in anonymous cooperative games. Participants and spectators to an ordeal by fire respond to the walks of others by sharing in their arousal, however only if they have had some prior association to at least one firewalker. Neuroscientific investigations show strong reward modulation in brain circuits as highly religious Christians respond to repetitive prayers. Strong social mind activations are found in response to intercessory prayers. Religious participants respond to healing prayers by exhibiting hypnotic down-regulation of executive neural circuitry, to different degrees depending on prior assumptions about the authority of a healer. I have explained such effects as "charismatic" factors that evolve to reliably and synchronously evoke, relatively automatically, widespread obedience, loyalty, and similar prosocial sentiments. I have also warned, however, that the diversity, magnitude, and duration of religion's effects on social-affective cognition remain poorly understood-that we know too little to draw definitive conclusions about the functions of religious traits and the systems that cause them.

\section{Evolutionary religious studies is relevant to the larger project of explaining human cooperative niche construction}

Dagen-H illustrates how solutions to risky coordination problems are possible without any help from creeping shamans, sandal wearing prophets, or celabate nuns. Even within the staunchly secular countercultures of late sixties Sweden, however, I think we can discern elements of designs that synchronously affect cooperation without explictly instructing cooperation: the underwear, the scantily clad women, the iconic symbols, the contests and songs ... Such designs do not appear to operate by supplying knowledge but rather by hijacking strategic sensibilities. We have seen that for risky cooperation, the mental gymnastics that accompany rational reflection may be damaging to cooperative outcomes because such reflection augments social predictive uncertainty. Needed instead to insure coordination are governing influences that distract partners from risks and from second-guessing other minds, while also motivating efficient exchange.

As naturalists gradually come to grips with the enormity of the project of explaining human cooperative niche construction (Sterelny 2010), we will do well, I think, to better understand religion's various designs and their positions among the marvellous and strange fabrications that have evolved to regulate commerce among strangers. 
Acknowledgments Thanks to Kim Sterelny, and two anonymous referees for helpful comments. Thanks to the Religion Culture and Cognition Group and The Center for Integrative Neuroscience, both at Aarhus University. I am grateful to the Victoria University Research Fund which supported open access to this article.

Open Access This article is distributed under the terms of the Creative Commons Attribution Noncommercial License which permits any noncommercial use, distribution, and reproduction in any medium, provided the original author(s) and source are credited.

\section{References}

Alvard MS, Nolin DA (2002) Rousseau's whale hunt? Coordination among big-game hunters. Curr Anthropol 43(4):533-559

Atkinson Q, Bourrat P (2010) Beliefs about god, the afterlife and morality support the role of supernatural policing in human cooperation. Evol Human Behav 32:41-49

Atran S, Norenzayan A (2004) Religion's evolutionary landscape: counterintuition, commitment, compassion, communion. Behav Brain Sci 27:713-770

Austin J (1962) Sense and sensibilia. Oxford University Press, New York

Bacharach M (2006) Beyond individual choice: teams and frames in game theory. Princeton University Press, Princeton

Batson CD, Schoenrade P, Ventis WL (1993) Religion and the individual: a social-psychological perspective. Oxford University Press, New York

Bellah R (1967) Civil religion in America. Daedalus 96:1-21

Bicchieri C (2006) The grammar of society: the nature and dynamics of social norms. Cambridge University Press, Cambridge

Binmore K (1998) Game theory and the social contract: just playing. MIT Press, Cambridge

Binmore K (2005) Natural justice. Oxford University Press, New York

Binmore K (2007) Game theory: a very short introduction. Oxford University Press, Oxford

Binmore K (2008) Do conventions need to be common knowledge? Topoi 27(1-2):17-27

Boyd R, Gintis H, Bowles S, Richerson P (2005) The evolution of altruistic punishment. The MIT Press, Cambridge

Boyer P, Lienard P (2006) Why ritualized behavior? Precaution systems and action parsing in developmental, pathological and cultural rituals. Behav Brain Sci 29(6):595-613

Bulbulia J (2009) Charismatic signalling. J Study Religion 3(4):518-551

Calcott B (2008) The other cooperation problem: generating benefit. Biol Philos 23(2):179-203

Camerer C (2003) Behavioral game theory: experiments in strategic interaction. Princeton University Press, Princeton

Chen D (2010) Club goods and group identity: evidence from islamic resurgence during the indonesian financial crisis, earlier version with model. J Polit Econ 118(2):300-354

Chwe M (2001) Rational ritual: culture, coordination, and common knowledge. Princeton University Press, Princeton

Critias (2010) The critias fragment, from sextus empiricus, adversus mathematicos (approx. 4th b.c.e.). See online translation: http://people.wku.edu/jan.garrett/302/critias.htm

Cronk L (1994) Evolutionary theories of morality and the manipulative use of signals. Zygon 29(1):81-101

Darley JM, Batson CD (1973) From jerusalem to jericho: a study of situational and dispositional variables in helping behavior. J Personal Soc Psychol 27(1):100-108

Gil-White F, Richerson P (2003) Large scale human cooperation and conflict. In: Nadel L (eds) Encyclopedia of cognitive science. Nature Publishing MacMillan, London

Ginges J, Hansen I, Norenzayan A (2009) Religion and support for suicide attacks. Psychol Sci 20(2):224-230

Haidt J, Patrick Seder J, Kesebir S (2008) Hive psychology, happiness, and public policy. J Legal Stud 37(June):S153-S156

Harman GH (1965) The inference to the best explanation. Philos Rev 74:88-95 
Henrich J (2006) Cooperation, punishment, and the evolution of human institutions. Science 312(5770):60-61

Henrich J (2009) The evolution of costly displays, cooperation, and religion:credibility enhancing displays and their implications for cultural evolution. Evol Human Behav 30:244-260

Hobbes T (1651) Leviathan (Project Gutenberg edn). Andrew Crooke, London

Hove M, Risen J (2009) It's all in the timing: Interpersonal synchrony increases affiliation. Soc Cogn 27(6):949-960

Hume D (1739) A treatise of human nature (Project Gutenburg edn). John Noon, London

Irons W (2001) Religion as hard-to-fake sign of commitment. Russell Sage Foundation, New York, pp 292-309

Johnson D (2005) God's punishment and public goods: a test of the supernatural punishment hypothesis in 186 world cultures. Human Nat 16(4):410-446

Johnston I (2010) The Mozi: a complete translation. Columbia University Press, New York

Kim Y, Sobel J (1995) An evolutionary approach to pre-play communication. Econometrica 63(5):1181-1193

Kincaid P (1986) The rule of the road: an international guide to history and practice. Greenwood Press, New York

Konvalinka I, Xygalatas D, Bulbulia J, Schjødt U, Jegindø E-M, Wallot S, Van Orden G, Roepstorff A (2011) Synchronized arousal between performers and related spectators in a fire-walking ritual. Proc Natl Acad Sci 108(20):8514-8519

Lanman J (2009) A secular mind: towards a cognitive anthropology of Atheism. PhD thesis

Lewis D (1969) Convention. Harvard University Press, Cambridge

MacLeod C, Sheehan P (2003) Hypnotic control of attention in the stroop task: a historical footnote. Conscious Cogn 12:201-203

Malhotra D (2010) (When) are religious people nicer? Religious salience and the "Sunday effect" on prosocial behavior. Judge Decis Making 5(2):138-143

Maynard Smith J (1982) Evolution and the theory of games. Cambridge University Press, New York

Mazar N, Amir O, Ariely D (2008) The dishonesty of honest people: A theory of self-concept maintenance. J Market Res 45(6):633-644

McNeill W (1995) Keeping together in time: dance and drill in human history. Cambridge University Press, Cambridge

Newson L (2009) Cultural versus reproductive success: why does economic development bring new tradeoffs? Am J Human Biol

Norenzayan A, Shariff A (2008) The origin and evolution of religious prosociality. Science 322(58):58-62

Oakley DA, Deeley Q, Halligan PW (2007) Hypnotic depth and response to suggestion under standardized conditions and during fmri scanning. Int J Clin Exp Hypn 55(1):32-58

Oakley DA, Halligan PW (2009) Hypnotic suggestion and cognitive neuroscience. Trends Cogn Sci 13(6):264-70

Ostrom E (1990) Governing the commons. Cambridge University Press, Cambridge

Ostrom E (2005) Understanding institutional diversity. Princeton University Press, Princeton, NJ

Randolph-Seng B, Nielsen M (2008) Is god really watching you? A response to shariff and norenzayan (2007) Int J Psychol Religion 18(2):119-122

Rousseau J (1992 [1755]) Discourse on the origin of inequality (Kindle edn). Hackett Publishing Company, Indianapolis

Rowthorn R (2011) Religion, fertility and genes: a dual inheritance model. Proc R Soc B 278(1717):2519-2527

Rubinstein A (1989) The electronic mail game: strategic behavior under "almost common knowledge". The Am Rev 79(3):385-391

Schelling T (1960) The strategy of conflict. Oxford University Press, New York

Schelling T (2006 [1978]) Micromotives and macrobehavior (Kindle edn). W.W. Norton \& Company, New York

Schjoedt U, Geertz A, Stødkild-Jørgensen H, Roepstorff A (2009) Highly religious participants recruit areas of social cognition in personal prayer. Soc Cogn Affect Neurosci 4(2):199-207

Schjoedt U, Stødkilde-Jørgensen H, Geertz A, Roepstorff A (2010) The power of charisma: perceived charisma inhibits the attentional and executive systems of believers in intercessory prayer. Soc Cogn Affect Neurosci 4(2):199-207 
Schjoedt U, Stodkildejorgensen H, Geertz A, Roepstorff A (2008) Rewarding prayers. Neurosci Lett 443(3): 165-168

Silk JB, Kaldor E, Boyd R (2000) Cheap talk when interests conflict. Animal Behav 59(2):423-432

Skyrms B (2004) The stag hunt and the evolution of social structure. Cambridge University Press, Cambridge

Sosis R (2003) Why aren't we all hutterites. Human Nat 14(2):91-127

Sosis R (2005) Does religion promote trust? the role of signaling, reputation, and punishment. Interdisciplinary. J Res Religion 1(1):1-30

Sosis R (2009) The adaptationist-byproduct debate on the evolution of religion: five misunderstandings of the adaptationist program. J Cogn Cult 9(3):315-332

Sosis R, Bressler E (2003) Co-operation and commune longevity: a test of the costly signaling theory of religion. Cross Cult Res 37(2):11-39

Sosis R, Ruffle B (2003) Religious ritual and cooperation: testing for a relationship on israeli religious and secular kibbutzim. Curr Anthropol 44(5):713-722

Sterelny K (2007) Snafus: an evolutionary perspective. Biol Theory 2(3):317-328

Sterelny K (2010) Minds: extended or scaffolded. Phenomenol Cogn Sci 9:465-481

Sterelny K (2011) The evolved apprentice. MIT Press, Cambridge

Sugden R (2003) The logic of team reasoning. Philos Explor 6:165-181

Turchin P (2006) War and peace and war (Kindle edn). Penguin Group, New York

Valdesolo P, DeSteno D (2011). Synchrony and the social tuning of compassion. Emotion 11(2):262-266

Van Huyck JB, Battalio RC, Beil RO (1990) Tacit coordination games, strategic uncertainty, and coordination failure. Am Econ Rev 80(1):234-248

Weber M (1958) The protestant ethic and the spirit of capitalism (translated by A. M. Henderson and T. Parsons). Scribner, New York

Wheatley P (1971) The pivot of the four quarters. Edinburgh University Press, Edinburgh

Whitehouse H (2004) Modes of religiosity: a cognitive theory of religious transmission. AltaMira Press, Lanham

Wilson D (2007) Evolution for everyone: how Darwin's theory can change the way we think about our lives. Delacorte Press, New York

Wiltermuth SS, Heath C (2008) Synchrony and cooperation. Psychol Sci 20:1-5

Young HP (1993) The evolution of conventions. Econometrica 61(1):57-84

Young P (1998) Individual strategy and social structure: an evolutionary theory of social institutions. Princeton University Press, Princeton 